\title{
Association of global and disease-specific health status with outcomes following continuous-flow left ventricular assist device implantation
}

Kelsey M. Flint ${ }^{*}$, John A. Spertus ${ }^{2}$, Fengming Tang ${ }^{2}$, Philip Jones ${ }^{2}$, Timothy J. Fendler ${ }^{2}$ and Larry A. Allen ${ }^{3}$

\begin{abstract}
Background: The prognostic value of heart failure specific and global health status before and after left ventricular assist device (LVAD) implantation in the usual care setting is not well studied.

Methods: We included 3,836 continuous-flow LVAD patients in the INTERMACS registry. Health status was measured pre-operatively and 3 months post-LVAD using the Kansas City Cardiomyopathy Questionnaire (KCCQ) and EuroQol visual analog scale (VAS). Primary outcomes were mortality/rehospitalization. Inverse propensity weighting was used to minimize bias from missing data.

Results: Pre-operative global and heart failure-specific health status were very poor: KCCQ median 34.6 (IQR 21.4-50.5); VAS median 43 (interquartile range (IQR) 25-65). Health status measures improved 3 months after LVAD placement: KCCQ median 69.3 (IQR 54.2-82.3); VAS median 75 (IQR 60-85). Pre-operative health status was not associated with death (unadjusted HR for lowest vs. highest score quartiles: 1.09 (0.85-1.41) KCCQ; 1.12 (0.85-1.49) VAS) or rehospitalization (unadjusted HR 0.83 (0.72-0.96) KCCQ; 0.99 (0.85-1.16) VAS). Three-month KCCQ was associated with mortality (unadjusted HR 2.17 (1.47-3.21); VAS was not (1.43 (0.94-2.17). Three-month KCCQ added incremental discriminatory value to the HeartMate II Risk Score for death (c-stat 0.60 to 0.66); VAS did not (c-stat 0.59 to 0.60). Three-month health status was associated with rehospitalization (unadjusted HR 1.31 (1.15-1.57) KCCQ; 1.24 (1.05-1.46) VAS), but did not add incremental discriminatory value (c-stat 0.52 to 0.55 and 0.54 , respectively).
\end{abstract}

Conclusions: These real-world data suggest that pre-operative health status has limited association with outcomes after LVAD. However, persistently low health status after surgery may independently signal higher risk for subsequent death. Further study is needed to determine the clinical utility of routinely collected health status data after LVAD implantation.

Keywords: Heart failure, Left ventricular assist device, Mechanical circulatory support, Health status, Quality of life

\section{Background}

Although survival and adverse events following left ventricular assist device (LVAD) placement have improved over time, 2-year survival after LVAD remains at 70\% in the modern era [1]. Predicting mortality after LVAD is challenging, with traditional risk models achieving a cstatistic between 0.61-0.70 [2-4]. Accordingly, there are

\footnotetext{
* Correspondence: Kelsey.flint@ucdenver.edu

${ }^{1}$ Division of Cardiology, University of Colorado Denver School of Medicine, Aurora, Colorado; Center for Cardiovascular Outcomes Research, 12631 East 17th Ave, B130, AuroraCo 80045 Denver, USA

Full list of author information is available at the end of the article
}

few data to guide clinicians in patient selection for this resource-intensive intervention, and current guidelines rely heavily on expert opinion [5]. Furthermore, longterm prognostication of patients who survive the acute, post-surgical phase after LVAD placement is not wellcharacterized. Therefore clinicians and patients often make management and goals of care decisions based upon personal, clinical and institutional experience.

One patient-reported measure that was initially hypothesized to improve prognostication following LVAD is health status. Health status encompasses symptom burden, functional status, and quality of life, and is best 
captured by validated questionnaires [6]. Poor health status is not only an important outcome to patients, but is also a strong independent predictor of subsequent hospitalization and mortality in patients with heart failure [7-10] and those undergoing cardiac surgery [11-14]. However, these findings do not necessarily extend to patients undergoing LVAD implantation, as pre-operative heart failure-specific health status was not associated with mortality after LVAD in the clinical trial setting [15]. Based on these findings, it has been hypothesized that heart failure treated with mechanical circulatory support may represent a relatively unique clinical situation, distinct from heart failure and other cardiac surgeries, in which the prognostic significance of health status may be largely reversed due to the profound impact of LVAD on the clinical course of the disease. However, while preprocedure health status may not be prognostic of longterm outcomes after LVAD implantation due to a major "resetting" of patients' health status with treatment, postprocedure health status may be associated with long-term outcomes, and assist in the planning for further treatment. Confirming these hypotheses in a contemporary, realworld setting may identify health status not only as a means for quantifying the benefits and risks of this treatment, but also as a tool to help guide clinical decisionmaking in the LVAD population.

To better characterize the association of pre- and post-implant health status scores with outcomes following LVAD in a usual care setting, we sought to build upon our prior work through the following: 1) confirm that, outside the clinical trial setting, pre-procedural health status was not prognostic of subsequent mortality and rehospitalization; 2) compare the relative strength of the association of global, rather than disease-specific health status with outcomes following LVAD; and 3) determine whether patients' health status after the acute, post-surgical phase was associated with subsequent survival and rehospitalization. To address these goals, we leveraged a large, multicenter North American observational registry to examine the association between baseline and 3-month post-LVAD global and disease-specific health status measures and subsequent survival and rehospitalization.

\section{Methods}

\section{Study design and population}

Interagency Registry for Mechanically Assisted Circulatory Support (INTERMACS) is a prospective, quality-assurance registry of de-identified data from all patients receiving a Food and Drug Administration approved mechanical circulatory support device at 165 participating centers. Follow-up clinical data are collected after device implantation at 1 week, 1 month, 3 months, 6 months, and every 6 months thereafter. Health status data are collected pre-operatively and at 3 and 6 months after
LVAD implantation and every 6 months thereafter. Hospitalization and mortality outcomes are recorded as they occur and at each follow-up period. All participating sites obtained Institutional Review Board (IRB) approval of the INTERMACS protocol. Individual patient informed consent was obtained, when mandated by the local IRB (some sites waived individual patient consent as the INTERMACS registry was viewed primarily as a quality improvement initiative). The current study did not qualify as human subjects' research because data were de-identified and previously collected, therefore it was exempt from Colorado Multiple Institutional Review Board review. Enrollment in INTERMACS began in June 2006; however, health status reporting was not emphasized until May 2012. We therefore restricted our analysis to patients enrolled in the INTERMACS database from May 2012 to December 2013. We included all adult ( $\geq 19$ years old) patients receiving a durable, continuous-flow LVAD. Baseline analyses included all patients who had baseline health status data available. Three-month analyses included only patients who survived to 3 months and had 3-month health status data available.

\section{Health status measures}

Heart failure-specific health status was measured using the Kansas City Cardiomyopathy Questionnaire (KCCQ). The KCCQ is a self-administered questionnaire that assesses the domains of physical limitation, heart failure symptoms, social limitation, self-efficacy, and health-related quality of life. The validity, reliability, and responsiveness to change in clinical status of the KCCQ have been previously reported [16]. Answers to the questionnaire are converted into a scale of 0 to 100 , with lower scores indicating worse health status. The overall summary score (OSS) was used in these analyses, and represents an average of the physical limitation, total symptoms, quality of life and social limitation domains.

The EuroQol 5-Dimensions (EQ-5D) questionnaire is a global health status measure that includes the Visual Analog Scale (VAS) [17]. The VAS asks patients to rate their overall health on a scale of 0 to 100 , with 0 representing "worst imaginable health" and 100 indicating "best imaginable health." Given the more readily interpretable data from the VAS and its proven association with mortality [18] and peak $\mathrm{VO}_{2}$ [19] in patients with heart failure, we used this scale as a measure of global health status.

\section{Statistical analysis}

The distribution of KCCQ and VAS scores pre-LVAD were heavily skewed towards poor values; therefore, questionnaire answers were divided into score quartiles rather than fixed ranges. Pre-operative characteristics were compared using chi-square tests for categorical 
variables and one-way analysis of variance for continuous variables.

Using the Kaplan-Meier method, we measured the raw association between pre-operative and 3-month KCCQ and VAS score quartiles with mortality and rehospitalization after LVAD. Patients were censored at the time of heart transplant, device explant or recovery. We assessed the incremental prognostic value of baseline and 3month KCCQ and VAS scores in predicting both mortality and rehospitalization when added to a base clinical model using Cox proportional hazards models. To assess whether the health status scores added prognostic information to standard clinical risk factors, we first adjusted for variables from the HeartMate II Risk Score (HMIIRS): age, albumin, creatinine, INR, and center volume [20]. We were not able to directly duplicate the HeartMate II Risk Score as the INTERMACS registry reports age as a categorical variable (50-59 years, 60-69 years, etc.) to protect patient identity, and the center volume variable in the HeartMate II Risk Score did not directly translate to the INTERMACS registry setting. Therefore, we included all of the Heartmate II Risk Score variables in a base Cox model, with age entered as a categorical variable (by decade), center volume calculated as the average number of INTERMACS-reported durable LVAD implants per year, and albumin, creatinine and INR as continuous variables.

Inverse propensity weighting (IPW) was used to decrease the effect of selection bias due to missing health status scores for both baseline and 3-month KCCQ and VAS. First, the probability of having health status scores available was calculated using a logistic regression model. Then the inverse of the probability was assigned to each patient with complete health status scores so that patients who were most like those with missing health status scores were given more weight, resulting in an IPW model that is more reflective of the general LVAD population included in the INTERMACS database. These weighted estimates were used in all analyses. IPW as a method for handling missing health status data in the INTERAMCS database has been previously validated [21] and used by other investigators [22].

Analysis was performed using SAS version 9.3 (Cary, $\mathrm{NC})$. A two-sided $p$-value $<0.05$ was considered significant.

\section{Results}

\section{Pre-operative characteristics}

The final cohort included 3,836 patients. Pre-operative global and heart failure-specific health status were very poor: VAS median 43 (interquartile range (IQR) 25-65); KCCQ median 34.6 (IQR 21.4-50.5). Health status measures improved 3 months after LVAD placement: VAS median 75 (IQR 60-85); KCCQ median 69.3 (IQR 54.282.3). Table 1 displays baseline patient characteristics stratified by pre-operative KCCQ score quartile. Patients in the lowest KCCQ score quartile (indicating worse health status) were more often female, INTERMACS profiles 1 or 2 at the time of device implant, and more frequently required dialysis or intra-aortic balloon pump prior to implant. Age group and implant strategy were not significantly associated with baseline KCCQ score quartile.

\section{Missing data}

At baseline, $42 \%$ of patients were missing KCCQ, and $43 \%$ of patients were missing VAS. At 3 months, $41 \%$ of patients were missing KCCQ, and $42 \%$ of patients were missing VAS. However, nearly $1 / 3$ of the patients missing either KCCQ or VAS at 3 months did not complete any of the 3-month follow-up. Of patients who completed the 3-month follow-up, 34\% and 35\% of patients were missing KCCQ and VAS, respectively. Baseline KCCQ and VAS were most commonly missing due to patient and administrative reasons, whereas 3-month heath status measures were most commonly missing due to administrative reasons. The primary reasons for baseline KCCQ and VAS to be missing were: "patient too sick" (29\% and 28\%, respectively), and "patient consent not obtained/patient not enrolled at time QoL instrument completion due" (30\% and $28 \%$, respectively). Besides missing the entire 3-month follow-up visit, 3-month KCCQ and VAS were most commonly missing because "coordinator was too busy or forgot to administer QoL instrument" (24\% and $21 \%$, respectively), "other" administrative reasons (13\% and $9 \%$, respectively) and "reason not given" ( $0.7 \%$ and $25 \%$, respectively). Patients missing baseline KCCQ data were more likely to be INTERMACS profile 1 at the time of implant, require IABP, mechanical ventilation and dialysis prior to implant and to receive LVAD for destination therapy (Additional file 1: Table S1).

\section{Pre-operative health status scores and mortality and rehospitalization}

In unadjusted, IPW Kaplan-Meier analyses, pre-operative KCCQ and VAS scores were not associated with mortality or rehospitalization (Fig. 1). For mortality, the unadjusted HR for lowest vs. highest score quartile of KCCQ was 1.09 (95\% CI 0.84-1.41), and was 1.12 (0.85-1.49) for VAS. For rehospitalization, the unadjusted HR for lowest vs. highest score quartile of the KCCQ was 0.83 (95\% CI 0.72-0.96), and was 0.99 (0.85-1.16) for VAS. Results were similar after adjusting for the variables in the HMIIRS (data not shown). Pre-operative KCCQ and VAS did not add incremental prognostic value when added to the variables included in the HMIIRS (Table 2).

\section{Three-month health status scores and mortality and rehospitalization}

In unadjusted, IPW Kaplan-Meier analysis, 3-month KCCQ scores were significantly associated with mortality, 
Table 1 Patient characteristics by baseline KCCQ score quartile

\begin{tabular}{|c|c|c|c|c|c|}
\hline & Overall & KCCQ Q1 & KCCQ Q2 & KCCQ Q3 & KCCQ Q4 \\
\hline $\mathrm{N}$ & 3836 & 552 & 558 & 556 & 559 \\
\hline KCCQ score median (IQR) & $34.6(21.4,50.5)^{*}$ & $14.3(9.6,18.2)$ & $28.1(25.3,31.5)$ & $41.1(37.5,45.6)$ & $63.8(56.3,74.5)$ \\
\hline \multicolumn{6}{|l|}{ Age in years ${ }^{a}$} \\
\hline $19-20$ & $150(4)$ & $12(2)$ & $13(2)$ & $16(3)$ & $20(4)$ \\
\hline 30-39 & $242(6)$ & $34(6)$ & $36(7)$ & $36(7)$ & $28(5)$ \\
\hline $40-49$ & $513(13)$ & $90(16)$ & $70(13)$ & $65(12)$ & $68(12)$ \\
\hline $50-59$ & $972(25)$ & $141(26)$ & $131(24)$ & $145(26)$ & $126(23)$ \\
\hline $60-69$ & $1330(35)$ & $189(34)$ & $207(37)$ & $177(32)$ & $212(38)$ \\
\hline $70-79$ & $597(16)$ & $80(15)$ & $97(17)$ & $111(20)$ & $101(18)$ \\
\hline$\geq 80$ & $32(0.8)$ & $6(1)$ & $4(0.7)$ & $6(1)$ & $4(0.7)$ \\
\hline Female $^{\mathrm{b}}$ & $807(21)$ & $148(27)$ & $133(24)$ & $97(17)$ & $82(15)$ \\
\hline \multicolumn{6}{|l|}{ INTERMACS profile $\mathrm{b}^{\mathrm{b} \S}$} \\
\hline 1 (Critical cardiogenic shock) & $500(13)$ & $66(12)$ & $27(5)$ & $23(4)$ & $26(5)$ \\
\hline 2 (Progressive decline) & $1361(36)$ & $237(43)$ & $197(34)$ & $188(34)$ & $195(35)$ \\
\hline 3 (Stable but inotrope dependent) & $1193(31)$ & $162(29)$ & $201(36)$ & $202(36)$ & $213(38)$ \\
\hline 4 (Resting symptoms) & $608(16)$ & $73(12)$ & $117(21)$ & $110(20)$ & $101(18)$ \\
\hline 5 (Exertion intolerant) & $112(3)$ & $7(1)$ & $14(3)$ & $25(5)$ & $13(2)$ \\
\hline 6 (Exertion limited) & $33(0.9)$ & $2(0.4)$ & $3(0.5)$ & $5(0.9)$ & $5(0.9)$ \\
\hline 7 (Advanced NYHA III) & $29(0.8)$ & $5(0.9)$ & $5(0.9)$ & $3(0.5)$ & $6(1)$ \\
\hline \multicolumn{6}{|l|}{ Device strategy ${ }^{a}$} \\
\hline Bridge to transplant & $788(21)$ & $97(18)$ & $112(20)$ & $102(18)$ & $141(25)$ \\
\hline Possible bridge to transplant & $1326(35)$ & $169(31)$ & $178(32)$ & $183(33)$ & $167(30)$ \\
\hline Destination therapy & $1,694(44)$ & $282(51)$ & $266(48)$ & $269(48)$ & $248(4)$ \\
\hline Other & $28(0.7)$ & $4(0.7)$ & $2(0.4)$ & $2(0.4)$ & $3(0.6)$ \\
\hline Dialysis within $48 \mathrm{~h}$ of implant ${ }^{\mathrm{c}}$ & $40(1)$ & $9(2)$ & $1(0.2)$ & $1(0.2)$ & $2(0.4)$ \\
\hline $\begin{array}{l}\text { Hemoglobin } g / L \\
(g / d L)^{b}\end{array}$ & $\begin{array}{l}114 \pm 21 \\
(11.4 \pm 2.1)\end{array}$ & $\begin{array}{l}112 \pm 21 \\
(11.2 \pm 2.1)\end{array}$ & $\begin{array}{l}116 \pm 20 \\
(11.6 \pm 2.0)\end{array}$ & $\begin{array}{l}118 \pm 20 \\
(11.8 \pm 2.0)\end{array}$ & $\begin{array}{l}118 \pm 20 \\
(11.8 \pm 2.0)\end{array}$ \\
\hline Sodium mmol/ $\mathrm{L}^{\mathrm{b}}$ & $135 \pm 5$ & $134 \pm 5$ & $135 \pm 5$ & $135 \pm 4$ & $136 \pm 4$ \\
\hline $\begin{array}{l}\text { Albumin } g / L \\
(\mathrm{~g} / \mathrm{dL})^{\mathrm{b}}\end{array}$ & $\begin{array}{l}34 \pm 7 \\
(3.4 \pm 0.7)\end{array}$ & $\begin{array}{l}34 \pm 06 \\
(3.4 \pm 0.6)\end{array}$ & $\begin{array}{l}35 \pm 7 \\
(3.5 \pm 0.7)\end{array}$ & $\begin{array}{l}35 \pm 6 \\
(3.5 \pm 0.6)\end{array}$ & $\begin{array}{l}36 \pm 6 \\
(3.6 \pm 0.6)\end{array}$ \\
\hline $\mid A B P^{\natural}$ & $918(24)$ & $146(26)$ & $89(16)$ & $86(16)$ & $71(13)$ \\
\hline Severe depression ${ }^{d}$ & $98(3)$ & $23(4)$ & $21(4)$ & $12(2)$ & $7(1)$ \\
\hline Working for income ${ }^{b}$ & $572(15)$ & $49(9)$ & $72(13)$ & $71(13)$ & $109(20)$ \\
\hline $6 \mathrm{MWT}^{\dagger}$ feet $^{\mathrm{b}}$ & $802 \pm 412$ & $607 \pm 517$ & $746 \pm 374$ & $843 \pm 367$ & $908 \pm 366$ \\
\hline Gait speed m/s & $0.9 \pm 0.8$ & $0.6 \pm 0.4$ & $0.9 \pm 1.1$ & $0.9 \pm 0.4$ & $1.0 \pm 1.0$ \\
\hline $\mathrm{VO}_{2} \max \mathrm{mL} / \mathrm{kg} / \mathrm{min}^{\mathrm{a}}$ & $11.1 \pm 3.7$ & $10.6 \pm 5.2$ & $10.6 \pm 2.4$ & $11.4 \pm 4.4$ & $11.1 \pm 2.7$ \\
\hline
\end{tabular}

All data are presented as $\mathrm{N}(\%)$ or mean \pm SD unless otherwise specified. All percents are rounded to the nearest whole number

${ }^{*} N=2225$

+6 min Walk Test

"Intra-aortic balloon pump

$\S$ Interagency Registry for Mechanically Assisted Circulatory Support

${ }^{\mathrm{a}} p=\mathrm{NS} ;{ }^{\mathrm{b}} p<0.001{ }^{\mathrm{c}} p=0.005 ;{ }^{\mathrm{d}} p=0.010^{\mathrm{e}} p=0.008$

which was primarily driven by the lowest health status quartile (Q1; Fig. 2). Unadjusted HR (95\% CI) for the lowest vs. highest KCCQ score quartile was 2.17 (1.47-3.21), and was 2.23 (1.49-3.34) after adjusting for the variables in the HMIIRS. Three-month VAS scores, however, were not associated with mortality (Fig. 2; Unadjusted HR (95\% CI) for lowest vs. highest score quartile was 1.43 (0.94-2.17)).

Three-month KCCQ and VAS were both statistically associated with rehospitalization following LVAD implantation (Fig. 2). The unadjusted HR (95\% CI) for 


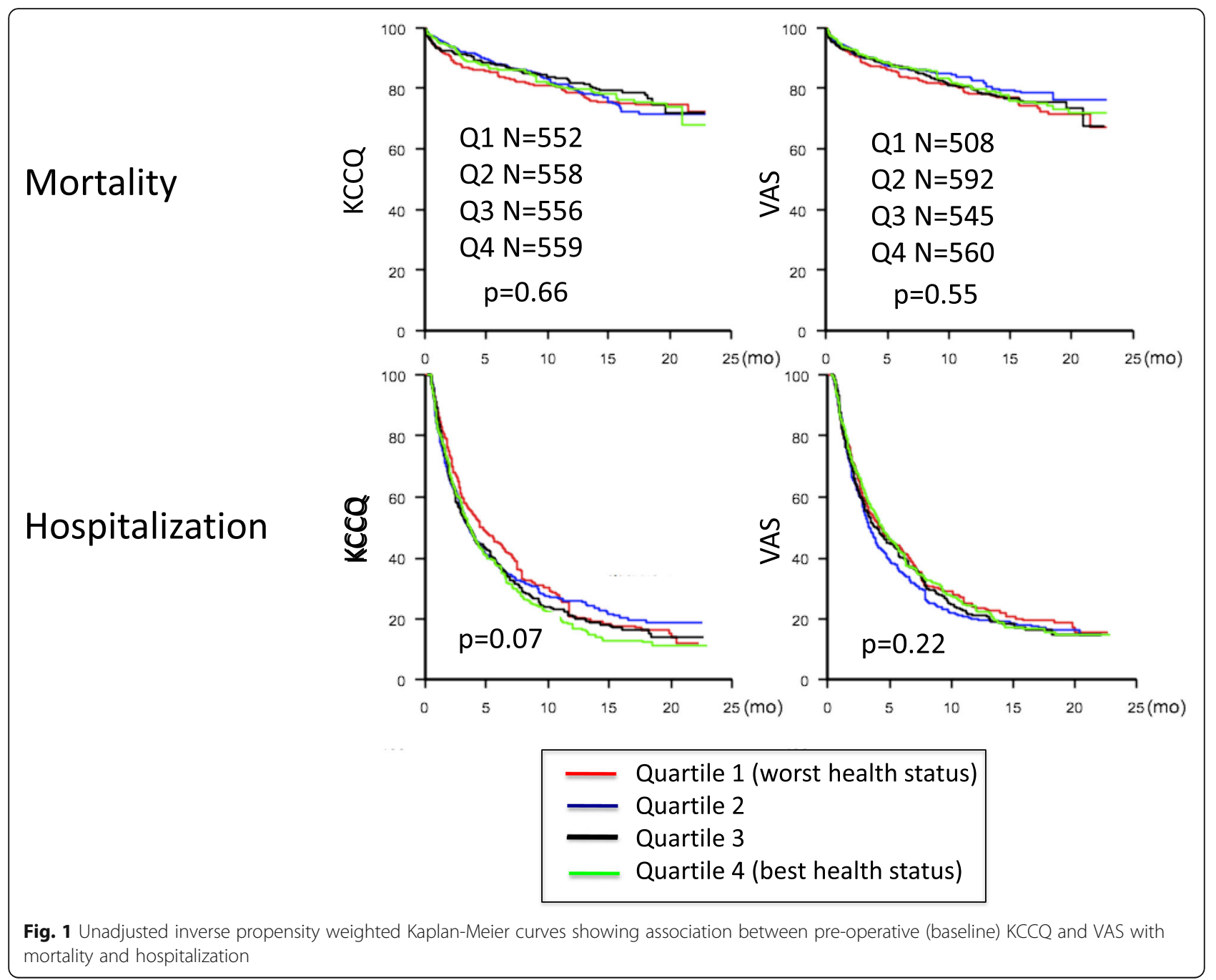

lowest vs. highest score quartile of KCCQ was 1.34 (1.15-1.57), and was 1.35 (1.14-1.60) after adjusting for the variables in the HMIIRS. For VAS, the unadjusted HR (95\% CI) was 1.24 (1.05-1.46), and was 1.20 (1.011.43) after adjusting for the variables in the HMIIRS.
The 3-month KCCQ added incremental discriminatory value for the outcome of mortality when added to the variables included in the HMIIRS (Table 2); VAS did not. Threemonth KCCQ and VAS scores did not add meaningful prognostic value for the outcome of rehospitalization (Table 2).

Table 2 Incremental prognostic value of weighted health status over the HeartMate II Risk Score in predicting mortality and rehospitalization after LVAD implantation

\begin{tabular}{lllll}
\hline & $\begin{array}{l}\text { C-statistic (base clinical } \\
\text { score only) } \\
\text { Outcome: } \\
\text { Mortality }\end{array}$ & $\begin{array}{l}\text { C-statistic (base clinical + } \\
\text { health status measure) }\end{array}$ & $\begin{array}{l}\text { C-statistic (base clinical } \\
\text { score only) } \\
\text { Outcome: } \\
\text { Rehospitalization }\end{array}$ & $\begin{array}{l}\text { C-statistic (base clinical + } \\
\text { health status measure) }\end{array}$ \\
\hline $\begin{array}{l}\text { Baseline KCCQ } \\
(N=2225)\end{array}$ & 0.60 & 0.61 & 0.51 & 0.50 \\
$\begin{array}{l}\text { Baseline EQ-5D VAS } \\
(N=2205)\end{array}$ & 0.60 & 0.60 & 0.51 & 0.52 \\
$\begin{array}{l}\text { 3-month KCCQ } \\
(N=2060)\end{array}$ & 0.60 & 0.66 & 0.52 & 0.55 \\
$\begin{array}{l}3-\text { month EQ-5D VAS } \\
(N=2005)\end{array}$ & 0.59 & 0.60 & 0.52 & 0.54 \\
\hline
\end{tabular}

Base clinical score was comprised of the variables included in the HeartMate II Risk Score [20] - age, albumin, creatinine, center volume, INR 


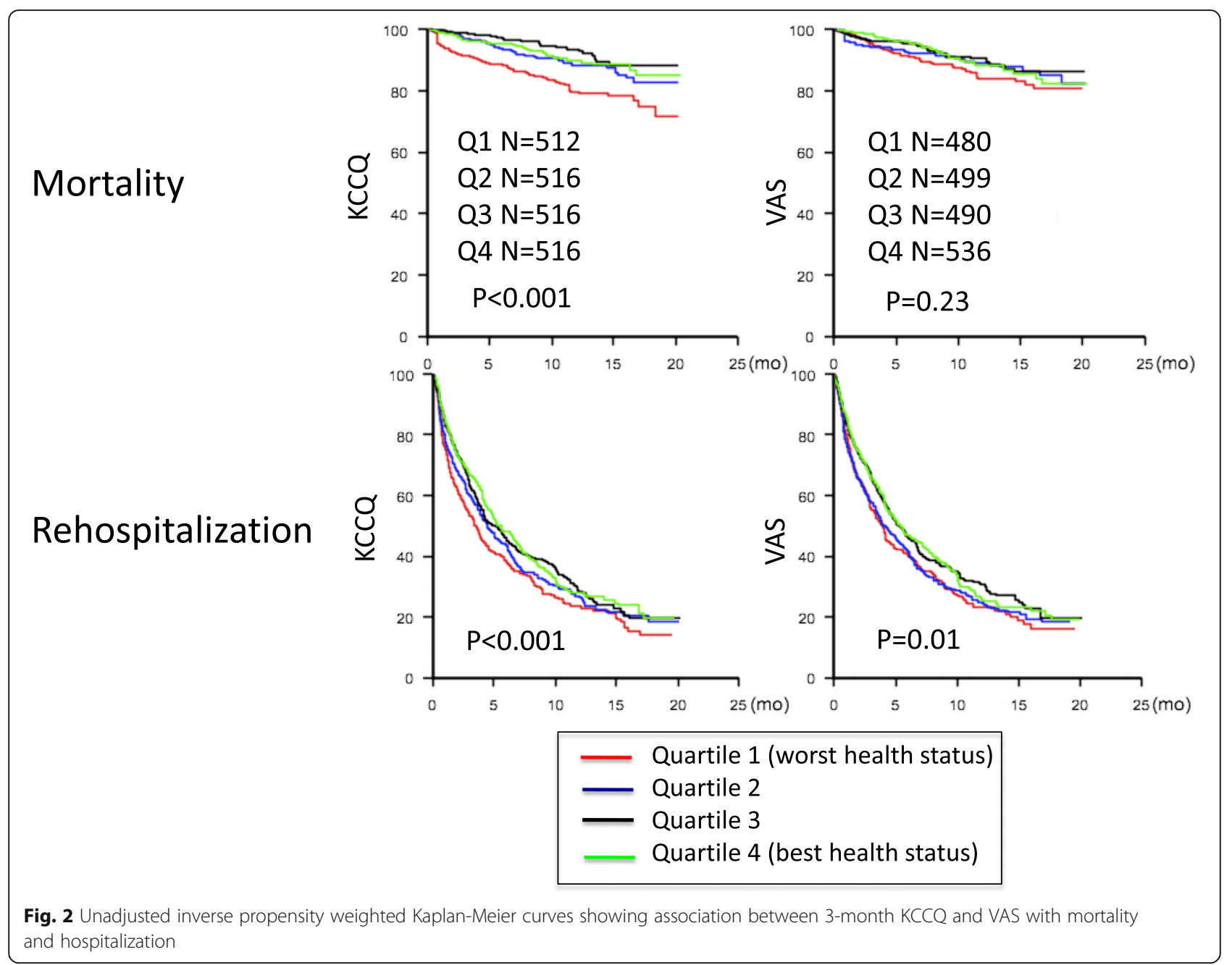

\section{Discussion}

In a large, prospective registry of patients receiving a durable, continuous-flow LVAD in the usual care setting, pre-operative health status was not associated with longterm mortality or rehospitalization, and did not add incremental discriminatory value to an existing validated risk model. However, 3-month post-implant heart failure-specific health status was associated with longterm mortality, but less so with hospitalization. These real-world results confirm our prior work in the clinical trial setting, which also found no association between baseline KCCQ and mortality following HeartMate II implantation [15]. Taken together, these data suggest that very poor pre-operative health status should not, in and of itself, preclude LVAD implantation. Mechanical circulatory support may represent a relatively unique clinical situation, distinct from heart failure and other cardiac surgeries, in which the intervention is so significant that it renders pre-operative heart failure-specific health status irrelevant. The current study also suggests that serial measurements of heart failure-specific health status following LVAD implantation may help inform clinical decision-making; however, further work is needed to identify the role health status might play in guiding patients' care once they have survived the acute, post-operative period.

\section{Current mortality risk prediction in the LVAD population}

The HeartMate II Risk Score is one of the most commonly used risk tools for pre-LVAD assessment. It was derived from a cohort of clinical trial patients who received continuous-flow LVAD [20,23], and has been validated in additional populations showing variable performance $[3,4,17,24]$. When applied to 201 continuous-flow LVAD recipients at Columbia University Medical Center, the HeartMate II Risk Score had a c-statistic of only 0.56 for 90-day mortality [3], but when applied to 269 patients treated at Barnes-Jewish Hospital, the c-statistic was 0.70 for 90 -day mortality, likely reflecting substantial differences in patient selection [4]. Loghmanpour et al. applied the HeartMate II Risk Score to all patients in the INTERMACS database, 
and reported an overall c-statistic of 0.57 (90-day mortality) and 0.60 (1-year mortality) [24], which is comparable to the results of the current study. The authors then utilized the INTERMACS database to demonstrate the significant promise of Bayesian analysis in predicting mortality in patients undergoing LVAD placement; however, these methods requires further adaptation before being easily applied in the clinical setting [24]. Given these limitations, additional efforts are needed improve prognostication in the LVAD population.

\section{Mortality}

The current study validated results from prior work which demonstrated that pre-operative KCCQ scores did not predict mortality or rehospitalization [15]. A potential reason for this finding is that LVAD therapy often improves patients' heart failure so significantly that preoperative health status is no longer relevant. Moreover, the long-term outcomes of LVAD patients are often dictated by factors unrelated to the left ventricle (e.g. stroke, right heart failure, infection, bleeding, renal dysfunction) [25]; indeed adverse events due to problems with the LVAD itself are unlikely to be predicted by a pre-operative patient-reported outcome such as health status. Pre-operative health status may still aid in patient selection for LVAD because those with much better health status prior to LVAD will have less opportunity to improve, and may not derive as much health status benefit from treatment compared to those with poorer pre-operative health status [26]. On the other hand, patients with poor pre-operative health status are more likely to suffer death or low health status following LVAD [22].

Interestingly, 3-month KCCQ was predictive of mortality and added incremental prognostic value to the base clinical model. Although overall health status improves dramatically following LVAD [27], not all patients will follow such a positive trajectory. Three-month KCCQ may thus help identify patients unlikely to enjoy the expected long-term benefit from their device due to ongoing heart failure or complications of the therapy. Prospective studies involving the serial measurement of health status after LVAD may help inform decisions regarding interventions targeting health status, and guide the timing of alternative treatment options, such as transplant for eligible patients, or eventual transition to palliative care.

\section{Rehospitalization}

In the current study, neither the base risk model nor health status measures provided meaningful discrimination for rehospitalizations in patients with a continuousflow, durable LVAD. In general, hospitalizations for heart failure are more challenging to predict than mortality
[28-32]. These problems may be magnified in the LVAD population, as the LVAD itself introduces many new reasons for why patients may be rehospitalized. Existing data report remarkably high hospital readmission rates after LVAD [33, 34]. The leading causes for hospital readmission in this population range from non-cardiac comorbidities [35], gastrointestinal bleeding [36], and device component infection [37] to recurrent heart failure [38] and progression of cardiac pathology [37]. The current study represents the challenges inherent in attempting to predict a very common outcome, and the need for further study.

\section{Future directions}

Determining the full clinical utility of serial health status measurements beyond 3 months after LVAD will require further investigation. Ultimately, a novel heath status tool tailored to the pre- and post-LVAD populations, which incorporates broader concepts of non-heart failure aspects of frailty,[39] may be the most promising method for incorporating health status into the care of patients both before and after LVAD implantation. The design of such a tool will require careful consideration of the heterogeneous outcomes patients with LVAD suffer, and may be most successful as a series of tools designed to predict each of the most common adverse outcomes following LVAD implantation. Preliminary data by Grady et al. describe the foundation for a novel health status tool designed for the post-LVAD period [40].

\section{Limitations}

The current study must be interpreted with care in the setting of its limitations. First, despite being the largest source of both global and disease-specific health status data in patients with LVAD, the INTERMACS registry is missing health status data in a significant minority of patients. We tried to minimize selection bias by utilizing IPW, a previously validated method for handling missing health status data that may decrease bias by preferentially weighting patients with health status measures who look like patients with missing health status measures [21, 22]. Such techniques are only partial solutions; however, despite these missing data concerns, INTERMACS has other significant advantages that make it one of the best sources to investigate this question. Second, we did not pursue analyses examining health status scores collected beyond 3 months post-LVAD due to very high rates of missing data at time points further from implantation. Finally, we were not able to separate device-related from patient-related causes of mortality and rehospitalization; therefore, we may have underestimated the predictive value of health status for patientrelated adverse outcomes. 


\section{Conclusion}

The current study builds upon prior work, confirming the absence of an association between baseline health status and mortality and hospitalization following LVAD implantation, perhaps because LVAD is such a significant intervention that it renders baseline health status irrelevant to these post-LVAD outcomes. However, in patients who do survive the acute post-operative period, heart failure-specific health status does hold prognostic significance. Future studies should explore interventions aimed at identifying patients with poor health status following LVAD, and focus on further refining the use of post-operative health status measurements in the routine clinical care of this complex patient population.

\section{Abbreviations}

EQ-5D: Euroqol 5-Dimensions; HMIIRS: HeartMate II Risk Score; HR: Hazards ratio; IABP: Intra-aortic balloon pump; INTERMACS: Interagency registry for mechanically assisted circulatory support; IPW: Inverse propensity weighting; KCCQ: Kansas City cardiomyopathy questionnaire; LVAD: Left ventricular assist device; QoL: Quality of life; VAS: Visual analog scale

\section{Acknowledgements}

None.

\section{Funding}

Dr. Allen is supported by K23HL105896 from the NHLB

\section{Availability of data and materials}

The data that support the findings of this study are available from the INTERMACS Registry, but restrictions apply to the availability of these data, which were used with permission from the INTERMACS Data Access, Analysis and Publications (DAAP) Committee, and so are not publicly available. Data are however available from the authors upon reasonable request and with permission of the INTERMACS DAAP Committee.

\section{Authors' contributions}

KF conceived and designed the research, drafted the manuscript, and interpreted the data. PJ and FT performed the statistical analysis, contributed to designing the research, and made critical revisions of the manuscript for important intellectual content. TF, JS and LA contributed to designing the research, contributed to data interpretation, and made critical revision of the manuscript for important intellectual content. All authors read and approved the manuscript and agree to be accountable for all aspects of the work.

\section{Competing interests}

John Spertus own the copyright to the KCCQ. All other authors have no sources of funding or conflicts of interest to disclose.

\section{Consent for publication}

not applicable.

\section{Ethics approval and consent to participate}

All participating sites obtained Institutional Review Board (IRB) approval of the INTERMACS protocol. Individual patient informed consent was obtained, when mandated by the local IRB for collection of health status data (some sites waived individual patient consent as the INTERMACS registry was viewed primarily as a quality improvement initiative).

\section{Publisher's Note}

Springer Nature remains neutral with regard to jurisdictional claims in published maps and institutional affiliations.

\section{Author details}

'Division of Cardiology, University of Colorado Denver School of Medicine, Aurora, Colorado; Center for Cardiovascular Outcomes Research, 12631 East 17th Ave "B130, AuroraCO 80045 Denver, USA. Saint Luke's Mid America
Heart Institute and University of Missouri - Kansas City, Kansas City, MO, USA. ${ }^{3}$ Division of Cardiology, Section of Advanced Heart Failure and Transplantation, University of Colorado Denver School of Medicine, Aurora, Colorado; Center for Cardiovascular Outcomes Research, Denver, CO, USA.

Received: 30 October 2016 Accepted: 7 March 2017

Published online: 14 March 2017

\section{Additional file}

Additional file 1: Comparison of baseline characteristics between patients with and without baseline Kansas City Cardiomyopathy Questionnaire (KCCQ) data. Baseline (or pre-operative) characteristics of patients who did and did not have baseline KCCQ data available. (DOCX $92 \mathrm{~kb}$ )

\section{Author details}

${ }^{1}$ Division of Cardiology, University of Colorado Denver School of Medicine, Aurora, Colorado; Center for Cardiovascular Outcomes Research, 12631 East 17th Ave "B130, AuroraCO 80045 Denver, USA. ${ }^{2}$ Saint Luke's Mid America Heart Institute and University of Missouri - Kansas City, Kansas City, MO, USA. ${ }^{3}$ Division of Cardiology, Section of Advanced Heart Failure and

Transplantation, University of Colorado Denver School of Medicine, Aurora, Colorado; Center for Cardiovascular Outcomes Research, Denver, CO, USA.

Received: 30 October 2016 Accepted: 7 March 2017

Published online: 14 March 2017

References

1. Kirklin JK, Naftel DC, Pagani FD, Kormos RL, Stevenson LW, Blume ED, Myers SL, Miller MA, Baldwin JT, Young JB. Seventh INTERMACS annual report: 15,000 patients and counting. J Heart Lung Transplant. 2015;34:1-10.

2. Levy WC. Potential Clinical Applications of the HeartMate II Risk Score. JAC. 2013;61:322-4

3. Thomas SS, Nahumi N, Han J, Lippel M, Colombo P, Yuzefpolskaya M, Takayama H, Naka Y, Uriel N, Jorde UP. Pre-operative mortality risk assessment in patients with continuous-flow left ventricular assist devices: Application of the HeartMate II risk score. J Heart Lung Transplant. 2014;33:675-81.

4. Adamo L, Nassif M, Tibrewala A, Novak E, Vader J, Silvestry SC, Itoh A, Ewald GA, Mann DL, LaRue SJ. The Heartmate Risk Score Predicts Morbidity and Mortality in Unselected Left Ventricular Assist Device Recipients and Risk Stratifies INTERMACS Class 1 Patients. JACC. 2015;3:1-8.

5. Feldman D, Pamboukian SV, Teuteberg JJ, Birks E, Lietz K, Moore SA, Morgan JA, Arabia F, Bauman ME, Buchholz HW, Deng M, Dickstein ML, El-Banayosy A, Elliot T, Goldstein DJ, Grady KL, Jones K, Hryniewicz K, John R, Kaan A, Kusne S, Loebe M, Massicotte MP, Moazami N, Mohacsi P, Mooney M, Nelson T, Pagani F, Perry W, Potapov EV, et al. The 2013 International Society for Heart and Lung Transplantation Guidelines for mechanical circulatory support: executive summary. J Heart Lung Transplant. 2013;2013:157-87.

6. Rumsfeld JS, Alexander KP, Goff DC, Graham MM, Ho PM, Masoudi FA, Moser DK, Roger VL, Slaughter MS, Smolderen KG, Spertus JA, Sullivan MD, Treat-Jacobson D, Zerwic JJ, on behalf of the American Heart Association Council on Quality of Care and Outcomes Research, Council on Cardiovascular and Stroke Nursing, Council on Epidemiology and Prevention, Council on Peripheral Vascular Disease, and Stroke Council: Cardiovascular Health: The Importance of Measuring Patient-Reported Health Status: A Scientific Statement From the American Heart Association. Circulation 2013, 127:2233-2249.

7. Heidenreich PA, Spertus JA, Jones PG, Weintraub WS, Rumsfeld JS, Rathore SS, Peterson ED, Masoudi FA, Krumholz HM, Havranek EP, Conard MW, Williams RE. Cardiovascular Outcomes Research Consortium: Health status identifies heart failure outpatients at risk for hospitalization or death. J Am Coll Cardiol. 2006:47:752-6.

8. Soto GE, Jones P, Weintraub WS, Krumholz HM, Spertus JA. Prognostic value of health status in patients with heart failure after acute myocardial infarction. Circulation. 2004:110:546-51.

9. Konstam V, Salem D, Pouleur H, Kostis J, Gorkin L, Shumaker S, Mottard I, Woods P, Konstam MA, Yusuf S. Baseline quality of life as a predictor of mortality and hospitalization in 5,025 patients with congestive heart failure. 
SOLVD Investigations. Studies of Left Ventricular Dysfunction Investigators. Am J Cardiol. 1996;78:890-5.

10. Kato N, Kinugawa K, Seki S, Shiga T, Hatano M, Yao A, Hirata Y, Kazuma K, Nagai R. Quality of Life as an Independent Predictor for Cardiac Events and Death in Patients With Heart Failure. Circ J. 2011;75:1661-9.

11. Rumsfeld JS, MaWhinney S, McCarthy M, Shroyer AL, Villanueva CB, O'Brien M, Moritz TE, Henderson WG, Grover FL, Sethi GK, Hammermeister KE. Health-related quality of life as a predictor of mortality following coronary artery bypass graft surgery. Participants of the Department of Veterans Affairs Cooperative Study Group on Processes, Structures, and Outcomes of Care in Cardiac Surgery. JAMA. 1999;281:1298-303.

12. Curtis LH, Phelps CE, McDermott MP, Rubin HR. The value of patientreported health status in predicting short-term outcomes after coronary artery bypass graft surgery. Med Care. 2002;40:1090-100.

13. Lindsay GM, Smith $L N$, Hanlon P, Wheatley DJ. The influence of general health status and social support on symptomatic outcome following coronary artery bypass grafting. Heart. 2001;85:80-6.

14. Koch CG, Li L, Lauer M, Sabik J, Starr NJ, Blackstone EH. Effect of functional health-related quality of life on long-term survival after cardiac surgery. Circulation. 2007;115:692-9.

15. Flint KM, Matlock DD, Sundareswaran KS, Lindenfeld J, Spertus JA, Farrar DJ, Allen LA. Pre-operative health status and outcomes after continuous-flow left ventricular assist device implantation. J Heart Lung Transplant. 2013;32: 1249-54.

16. Green C, Porter C, Bresnahan D, Spertus J. Development and evaluation of the Kansas City Cardiomyopathy Questionnaire: a new health status measure for heart failure. J Am Coll Cardiol. 2000;35:1245.

17. Group EQ. EuroQol-a new facility for the measurement of health-related quality of life. Health Policy. 1990;16:199-208.

18. Ambrosy AP, Hernandez AF, Armstrong PW, Butler J, Dunning A, Ezekowitz JA, Felker GM, Greene SJ, Kaul P, McMurray JJ, Metra M, O'Connor CM, Reed SD, Schulte PJ, Starling RC, Wilson Tang WH, Voors AA, Mentz RJ: The clinical course of health status and association with outcomes in patients hospitalized for heart failure: insights from ASCEND-HF. Eur J Heart Fail. 2015.

19. Flynn KE, Lin L, Ellis SJ, Russell SD, Spertus JA, Whellan DJ, Piña IL, Fine LJ, Schulman KA, Weinfurt KP. Outcomes, health policy, and managed care: Relationships between patient-reported outcome measures and clinical measures in outpatients with heart failure. Am Heart J. 2009;158:S64-71.

20. Cowger J, Sundareswaran K, Rogers JG, Park SJ, Pagani FD, Bhat G, Jaski B, Farrar DJ, Slaughter MS. Predicting Survival in Patients Receiving Continuous Flow Left Ventricular Assist Devices: The HeartMate II Risk Score. J Am Coll Cardiol. 2013;61:313-21.

21. Grady KL, Andrei A-C, Naftel DC, Meyers S, Dew MA, Idrissi KA, Weidner G, Wissman S, Kirklin JK, Spertus J: Abstract: Approaches to Missing Data Due to Illness Severity in Health-related Quality of Life Assessment. Circ Cardiovasc Qual Outcomes 2015:8:A277.

22. Arnold SV, Jones PG, Allen LA, Cohen DJ, Fendler TJ, Holtz JE, Aggarwal S, Spertus JA. Frequency of Poor Outcome (Death or Poor Quality of Life) After Left Ventricular Assist Device for Destination Therapy: Results From the INTERMACS Registry. Circulation heart failure. 2016;9:e002800.

23. Spertus JA, Jones PG. Development and Validation of a Short Version of the Kansas City Cardiomyopathy Questionnaire. Circ Cardiovasc Qual Outcomes. 2015;8:469-76

24. Loghmanpour NA, Kanwar MK, Druzdzel MJ, Benza RL, Murali S, Antaki JF: A New Bayesian Network-Based Risk Stratification Model for Prediction of Short-term and Long-term LVAD Mortality. ASAIO J. 2015;1:313-323.

25. Kirklin JK, Naftel DC, Pagani FD, Kormos RL, Stevenson LW, Blume ED, Miller MA, Baldwin JT, Young JB. Sixth INTERMACS annual report: A 10,000-patient database. J Heart Lung Transplant. 2014:33:555-64.

26. Grady KL, Naftel D, Stevenson L, Amanda Dew M, Weidner G, Pagani FD, Kirklin JK, Myers S, Baldwin T, Young J. Overall quality of life improves to similar levels after mechanical circulatory support regardless of severity of heart failure before implantation. J Heart Lung Transplant. 2014;33:412-21.

27. Rogers JG, Aaronson KD, Boyle AJ, Russell SD, Milano CA, Pagani FD, Edwards BS, Park SJ, John R, Conte JV, Farrar DJ. Slaughter MS, for the HeartMate II Clinical Investigators: Continuous Flow Left Ventricular Assist Device Improves Functional Capacity and Quality of Life of Advanced Heart Failure Patients. J Am Coll Cardiol. 2010;55:1826-34.

28. Hernandez AF, Greiner MA, Fonarow GC, Hammill BG, Heidenreich PA, Yancy CW, Peterson ED, Curtis LH. Relationship between early physician follow-up and 30-day readmission among Medicare beneficiaries hospitalized for heart failure. JAMA. 2010;303:1716-22.

29. Jencks SF, Williams MV, Coleman EA. Rehospitalizations among patients in the Medicare fee-for-service program. N Engl J Med. 2009;360:1418-28.

30. Ross JS, Mulvey GK, Stauffer B, Patlolla V, Bernheim SM, Keenan PS, Krumholz HM. Statistical models and patient predictors of readmission for heart failure: a systematic review. Arch Intern Med. 2008;168:1371-86.

31. Zaya M, Phan A, Schwarz ER. Predictors of re-hospitalization in patients with chronic heart failure. World J Cardiol. 2012;4:23-30.

32. Hernandez MB, Schwartz RS, Asher CR, Navas EV, Totfalusi V, Buitrago I, Lahoti A, Novaro GM. Predictors of 30-Day Readmission in Patients Hospitalized With Decompensated Heart Failure. Clin Cardiol. 2013;36:542-7.

33. Khazanie P, Hammill BG, Patel CB, Eapen ZJ, Peterson ED, Rogers JG, Milano CA, Curtis LH, Hernandez AF. Trends in the use and outcomes of ventricular assist devices among medicare beneficiaries, 2006 through 2011. J Am Coll Cardiol. 2014;63:1395-404

34. Dunlay SM, Haas LR, Herrin J, Schilz SR, Stulak JM, Kushwaha SS, Shah ND. Use of Post-acute Care Services and Readmissions After Left Ventricular Assist Device Implantation in Privately Insured Patients. J Card Fail. 2015;21: 816-23.

35. Hernandez RE, Singh SK, Hoang DT, Ali SW, Elayda MA, Mallidi HR, Frazier $\mathrm{OH}$, Meyers DE. Present-Day Hospital Readmissions after Left Ventricular Assist Device Implantation: A Large Single-Center Study. Tex Heart Inst J. 2015:42:419-29.

36. Forest SJ, Bello R, Friedmann P, Casazza D, Nucci C, Shin JJ, D'Alessandro D, Stevens G, Goldstein DJ. Readmissions After Ventricular Assist Device: Etiologies, Patterns, and Days Out of Hospital. Ann Thorac Surg. 2013;95: $1276-81$.

37. Smedira NG, Hoercher KJ, Lima B, Mountis MM, Starling RC, Thuita L, Schmuhl DM, Blackstone EH. Unplanned Hospital Readmissions After HeartMate II Implantation. JACC. 2013;1:31-9.

38. Tsiouris A, Paone G, Nemeh HW, Brewer RJ, Morgan JA. Factors determining post-operative readmissions after left ventricular assist device implantation. J Heart Lung Transplant. 2014;33:1041-7.

39. Flint KM, Matlock DD, Lindenfeld J, Allen LA. Frailty and the selection of patients for destination therapy left ventricular assist device. Circulation heart failure. 2012:5:286-93.

40. Grady KL, Magasi S, Hahn EA, Buono S, McGee EC, Yancy C. Health-related quality of life in mechanical circulatory support: Development of a new conceptual model and items for self-administration. J Heart Lung Transplant. 2015:34:1-13,

\section{Submit your next manuscript to BioMed Central and we will help you at every step:}

- We accept pre-submission inquiries

- Our selector tool helps you to find the most relevant journal

- We provide round the clock customer support

- Convenient online submission

- Thorough peer review

- Inclusion in PubMed and all major indexing services

- Maximum visibility for your research

Submit your manuscript at www.biomedcentral.com/submit
) Biomed Central 